\title{
A distilled fire of thirteen hells - Jens Baggesen between the Germans and the Danes
}

Blicher, Henrik

Published in:

Deutsch-dänische Kulturbeziehungen im 18. Jahrhundert

Publication date:

2018

Document version

Publisher's PDF, also known as Version of record

Document license:

Unspecified

Citation for published version (APA):

Blicher, H. (2018). A distilled fire of thirteen hells - Jens Baggesen between the Germans and the Danes. In S. P. Hansen, \& S. Stockhorst (Eds.), Deutsch-dänische Kulturbeziehungen im 18. Jahrhundert V\&R unipress. Schriften des Frühneuzeitzentrums Potsdam Vol. 9 


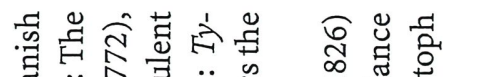

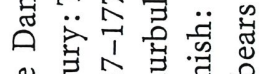

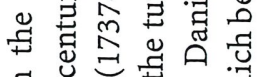

. $\exists$ \&

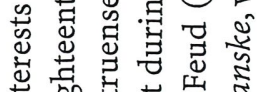

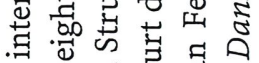

㐘芯

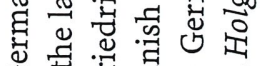
of

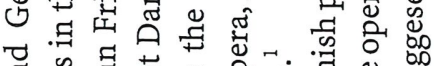

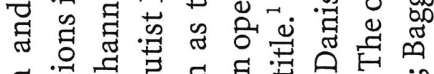
동

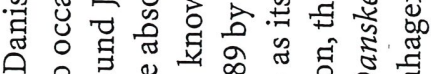

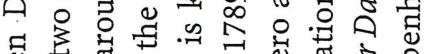

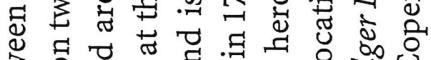

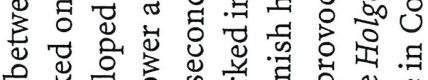
宩

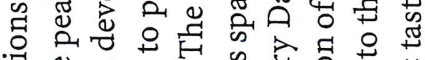

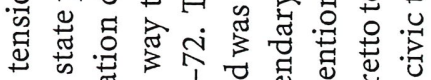

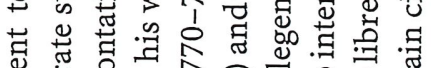

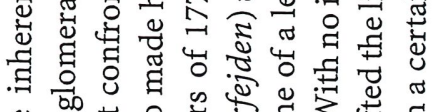

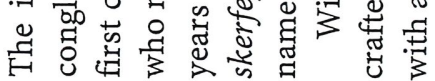

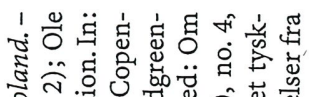

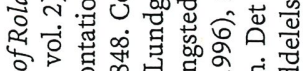

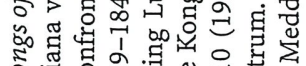
s. fo

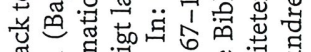

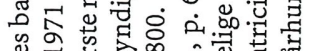

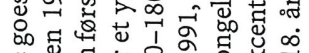

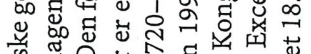
宛泀

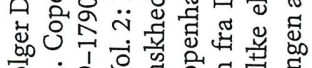

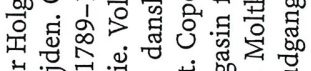

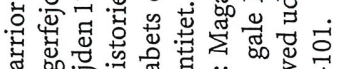

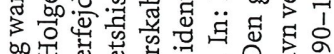

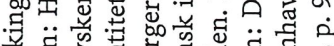

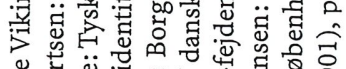

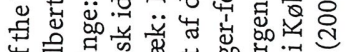

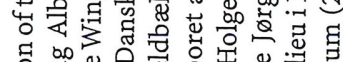

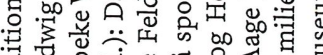

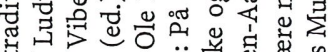

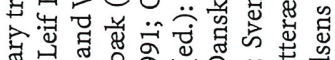

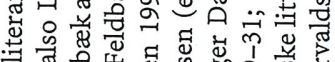

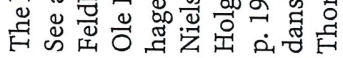

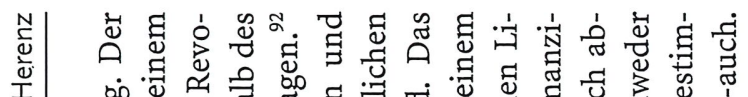
o.

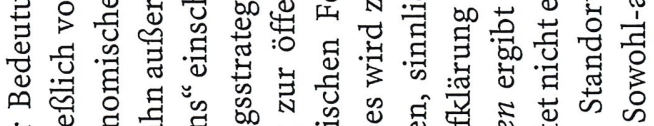

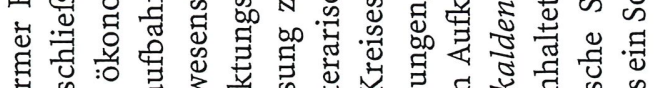

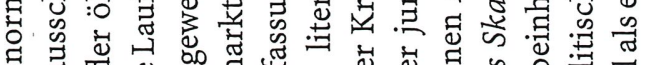
है च

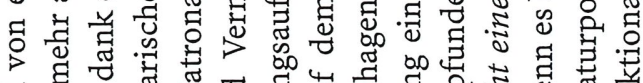

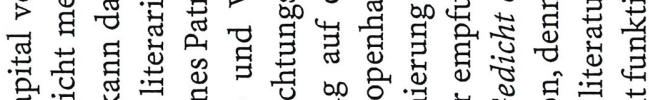

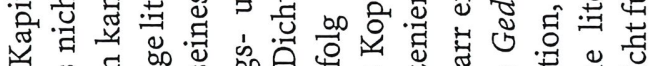

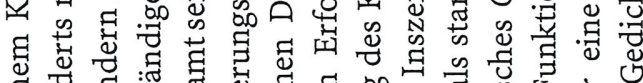

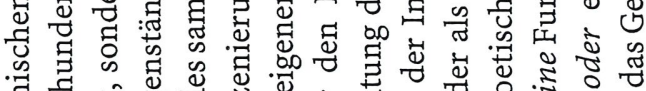

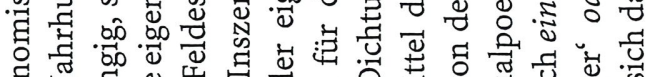

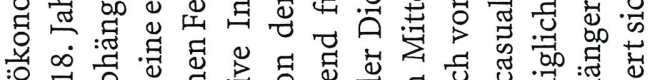
동 0

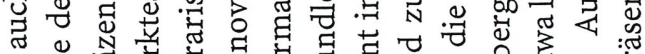

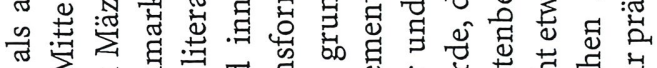

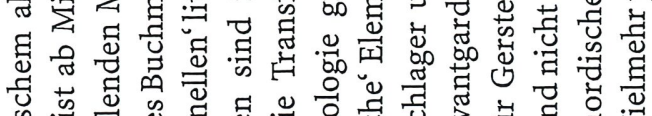

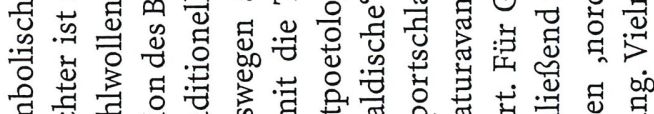




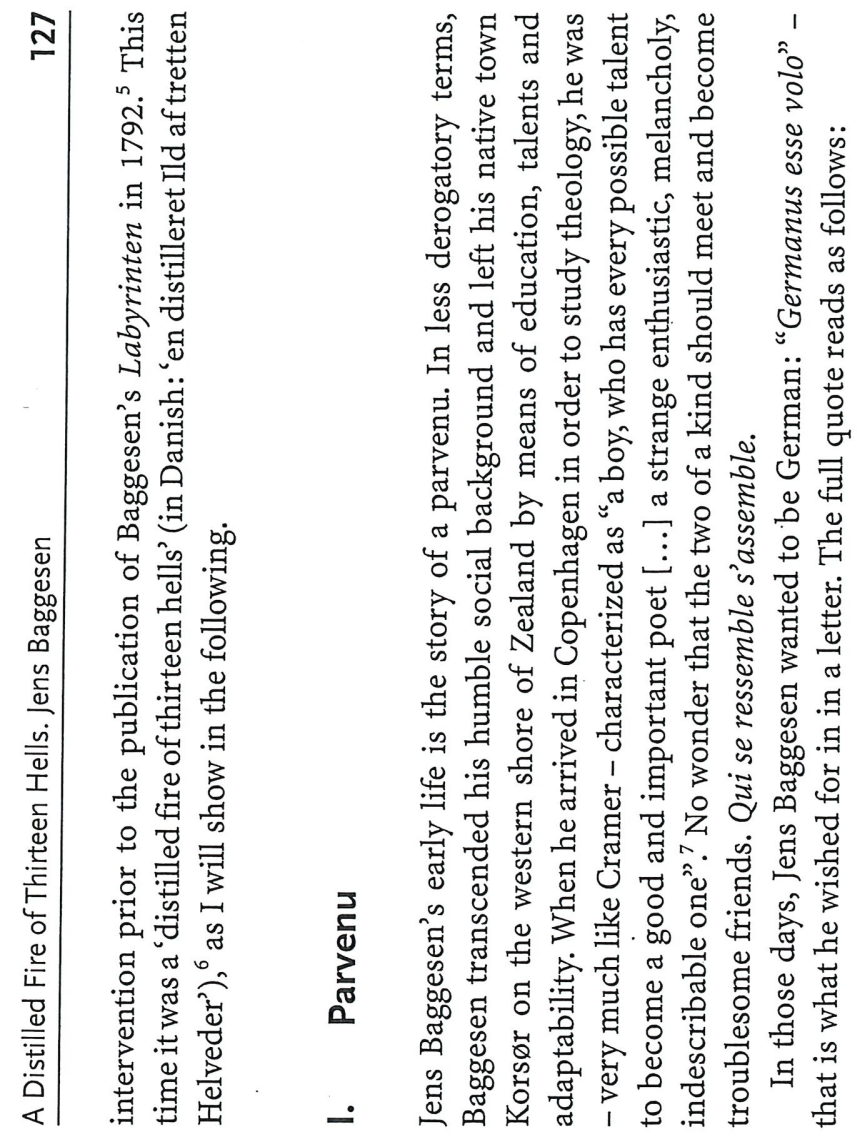

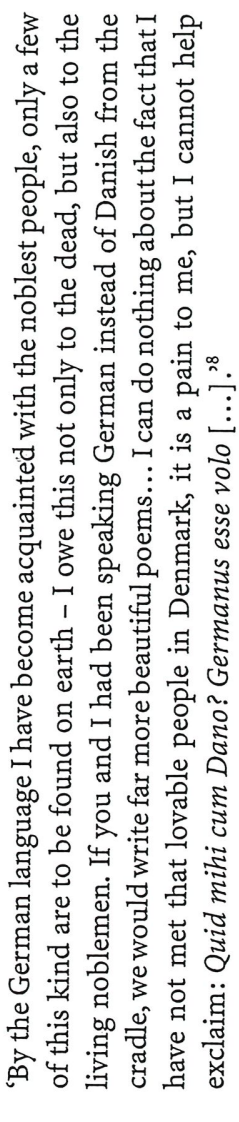

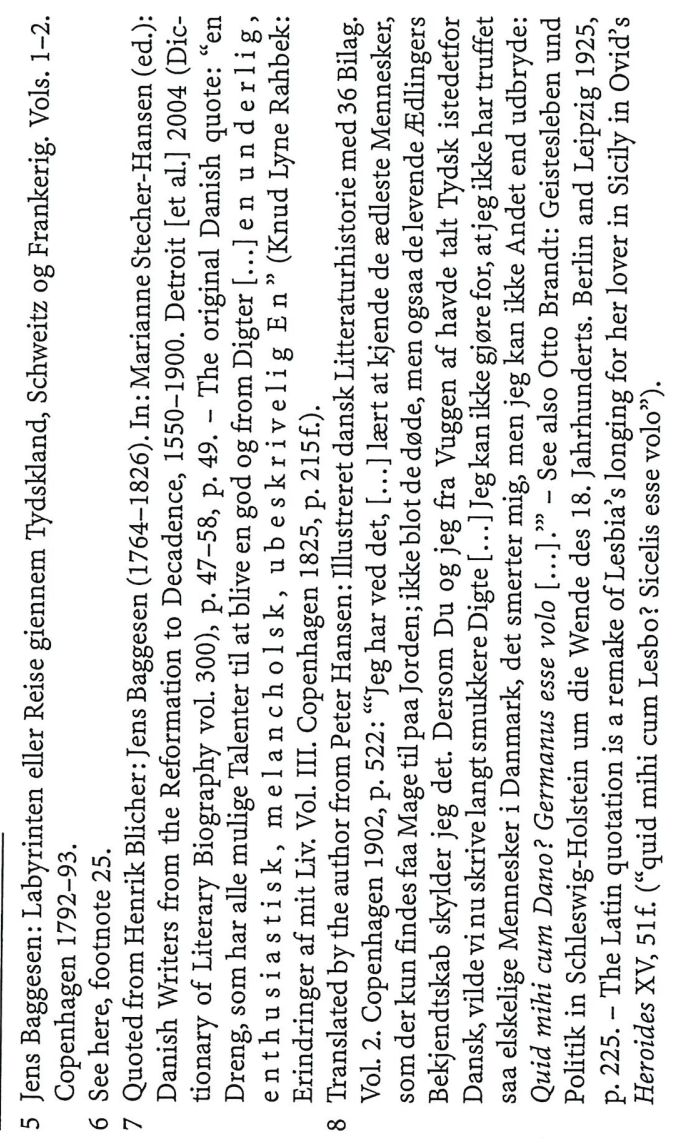

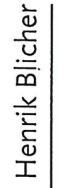

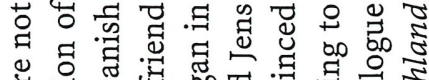

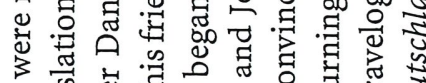

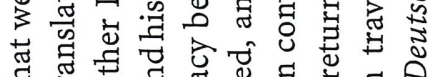

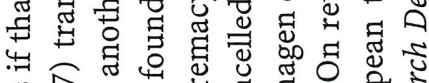

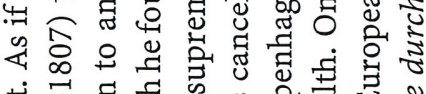

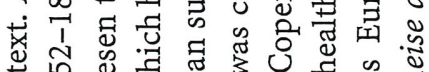

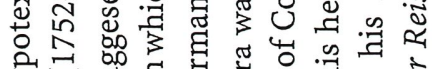

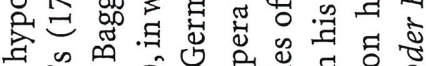
๙ 㞼 毒 के

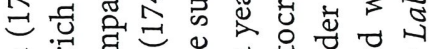

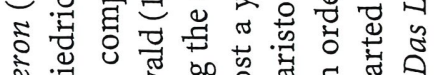

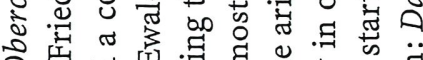

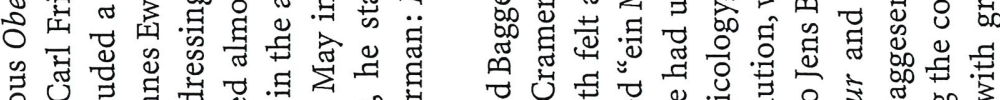

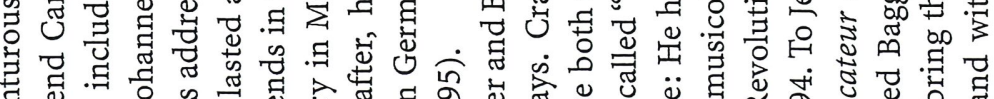

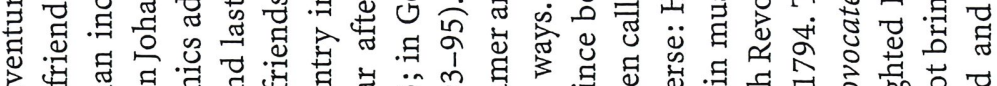

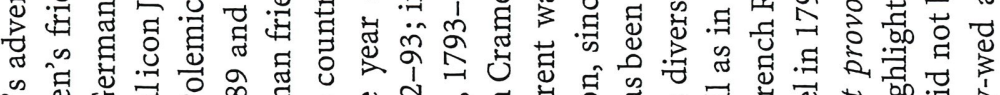
क जี

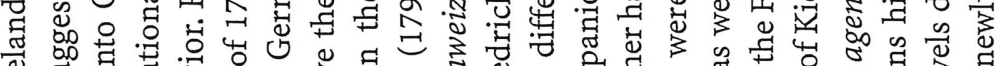

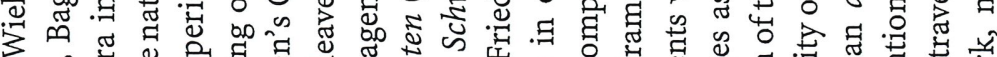
री

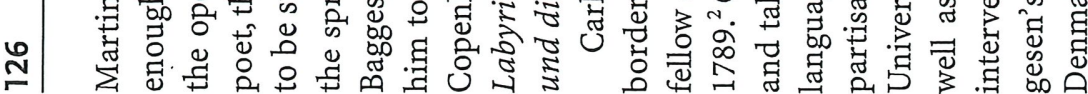

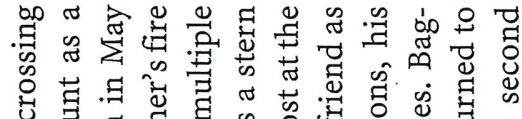

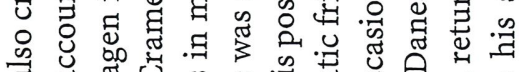
ब

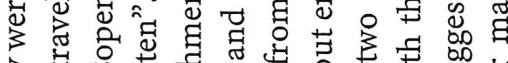

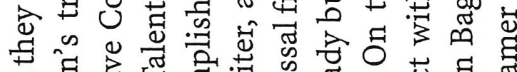

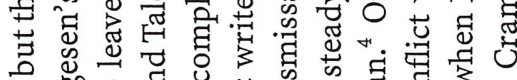
sิ

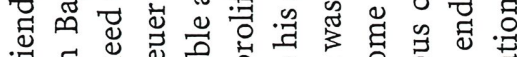

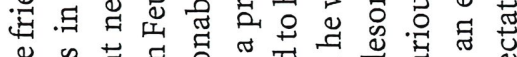

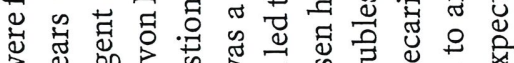
政 会可

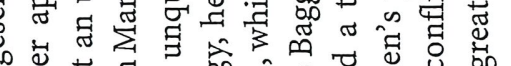

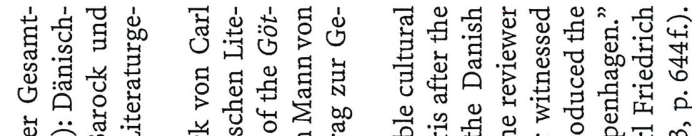

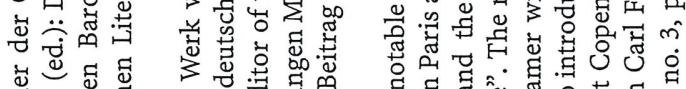

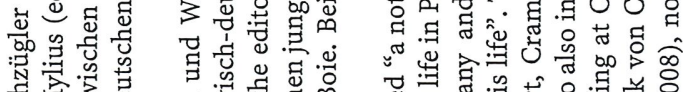

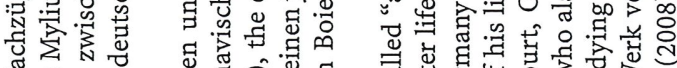

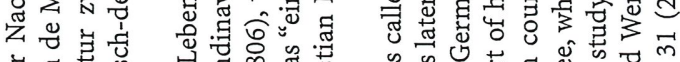

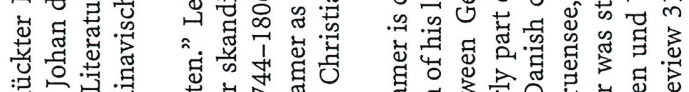

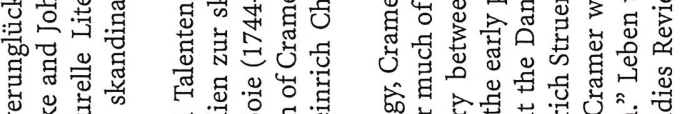

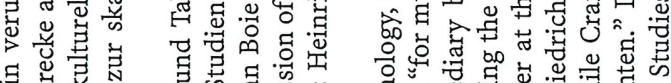

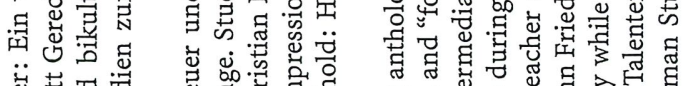

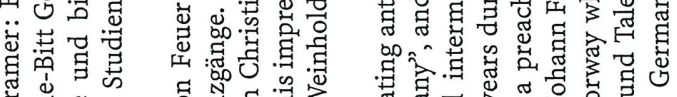

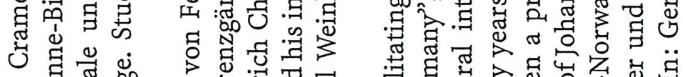

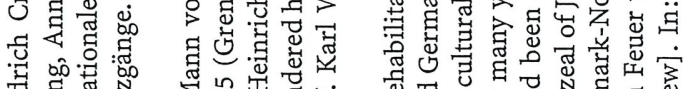

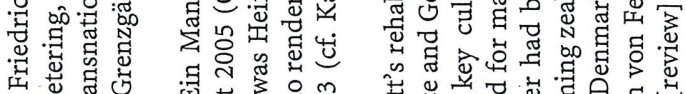

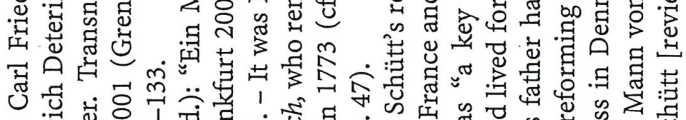

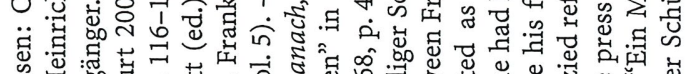

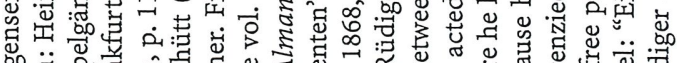

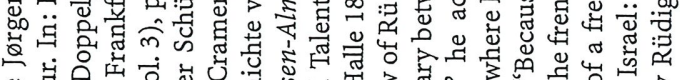

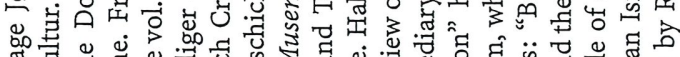

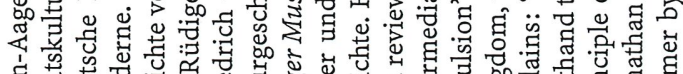
H) 


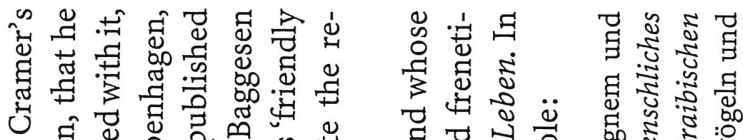

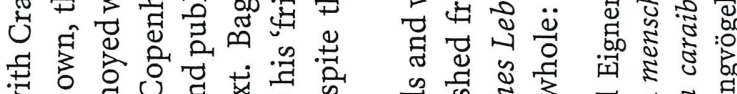
3. 表.

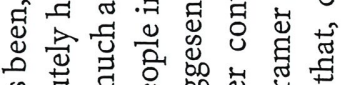

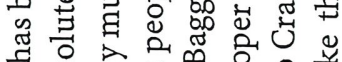

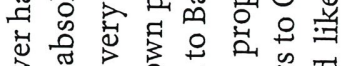

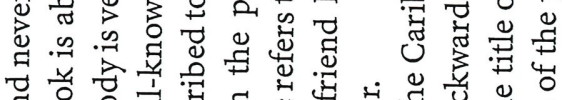

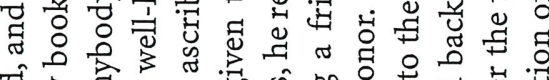

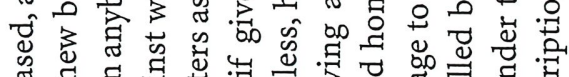

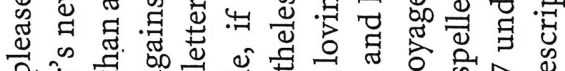

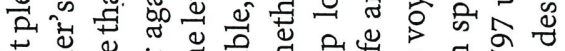

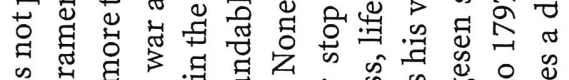
.

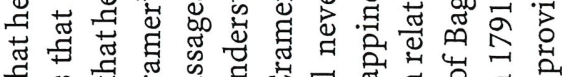

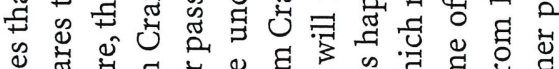

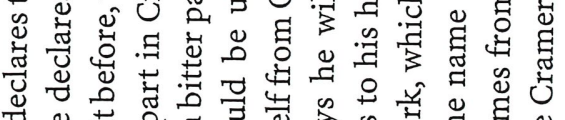
ช

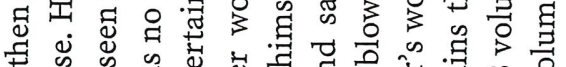
先

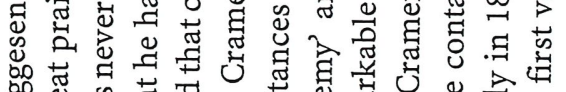

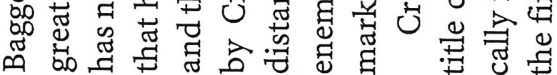

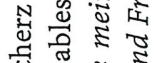

का

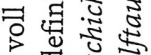

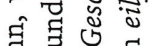

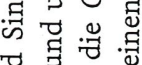

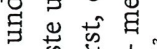

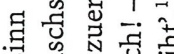

要

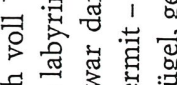

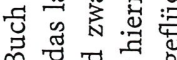
毒焉自空

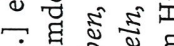

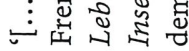

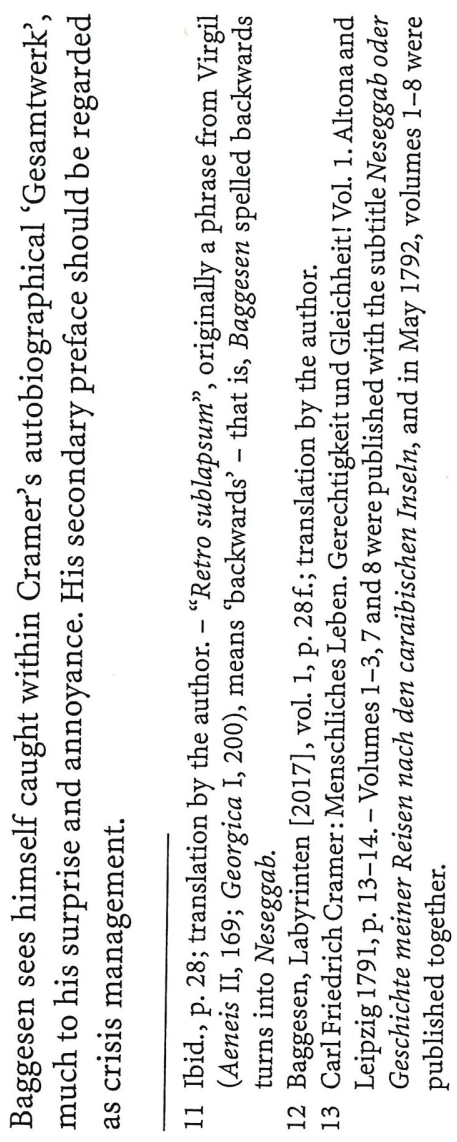

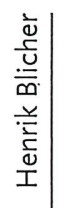

专泀营

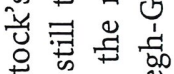

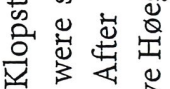

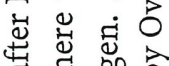

压苛合

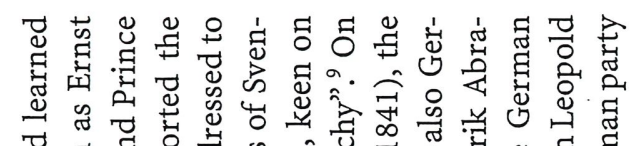

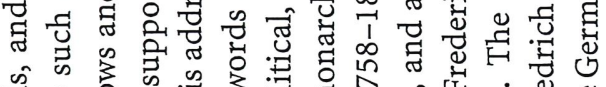

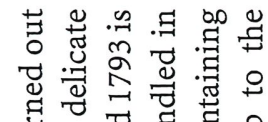

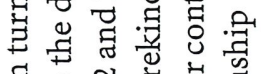

U.

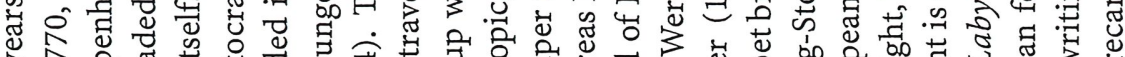

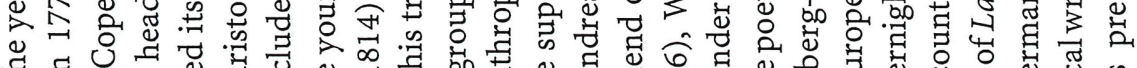

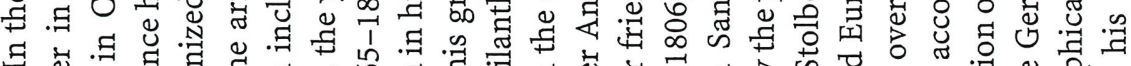

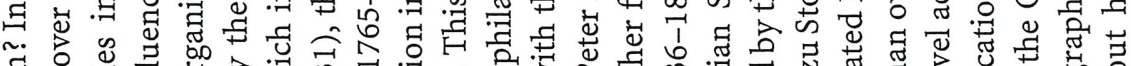

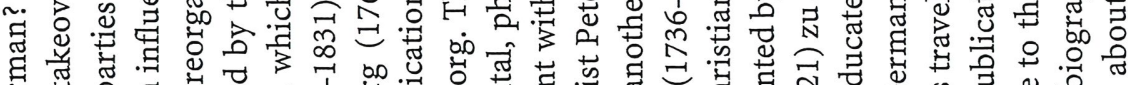

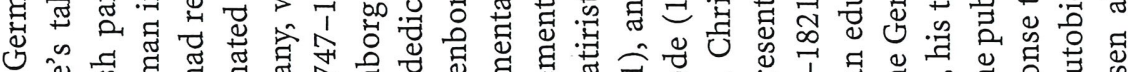
心

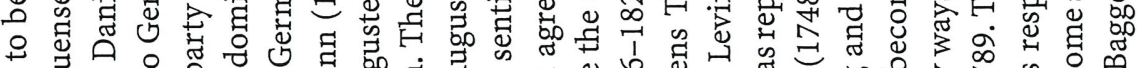

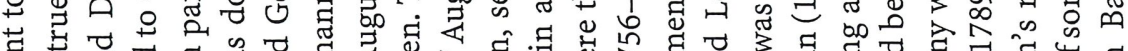

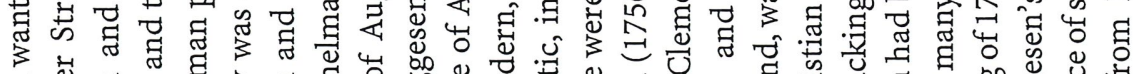

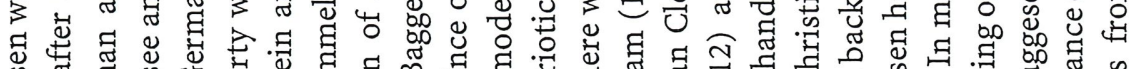

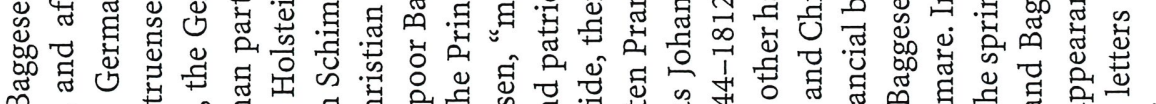

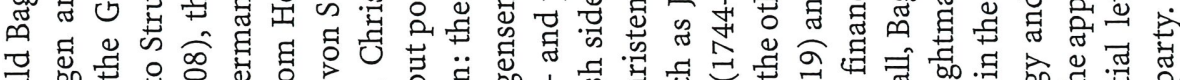
节品

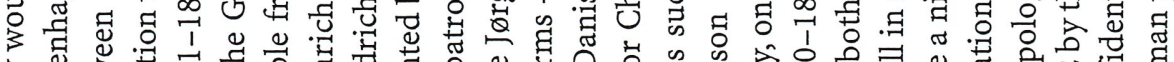
$\stackrel{\infty}{\sim}$

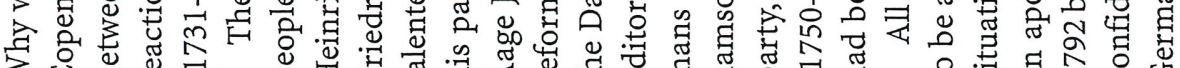

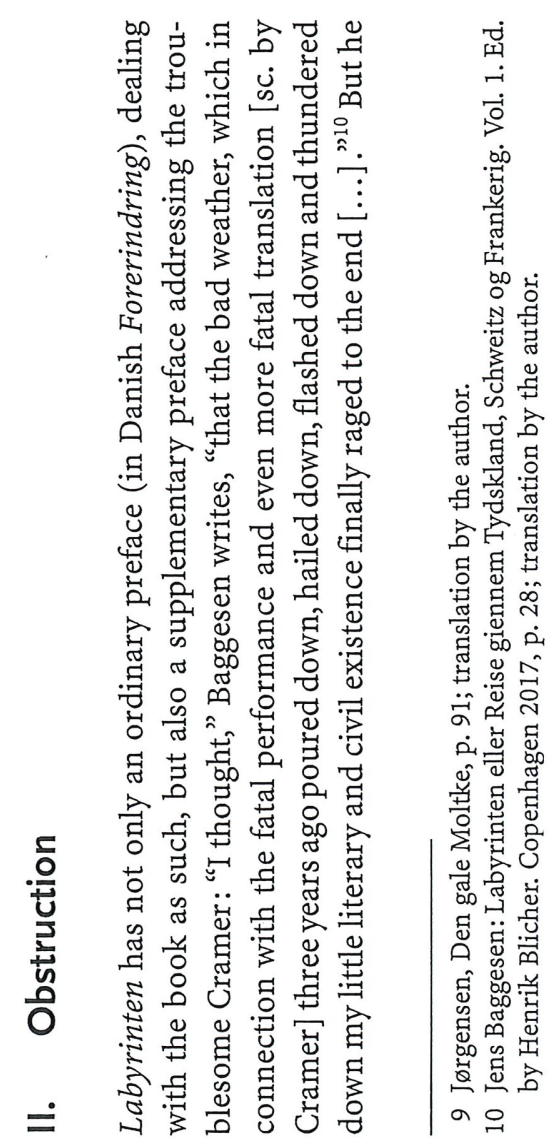



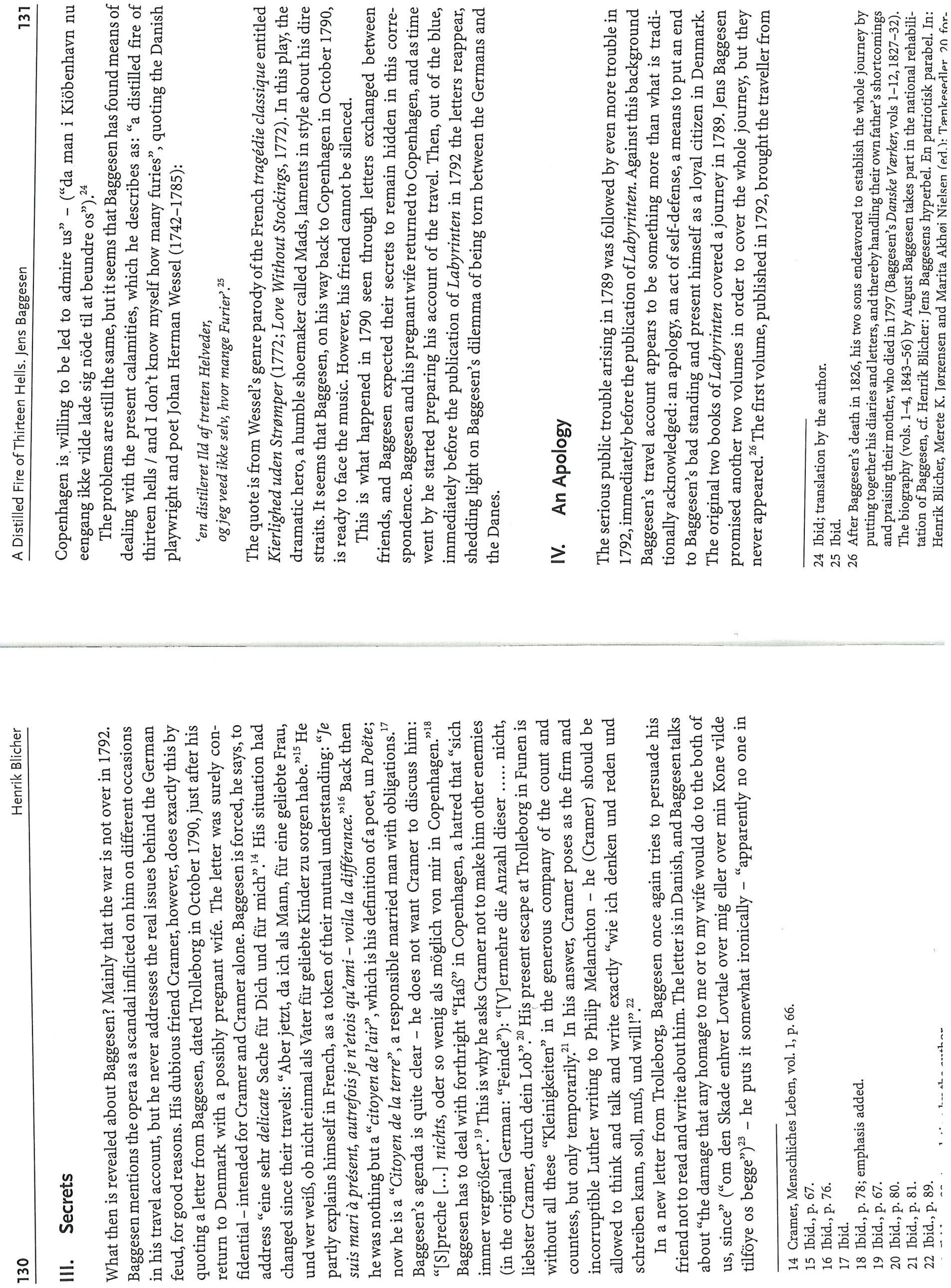


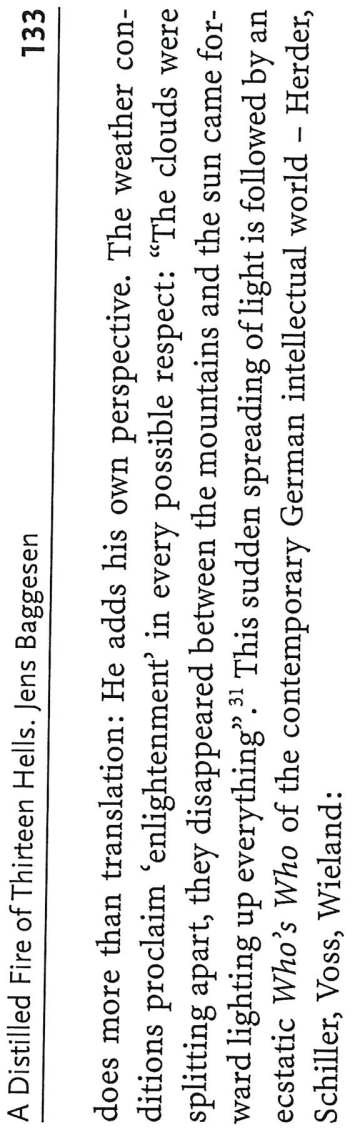

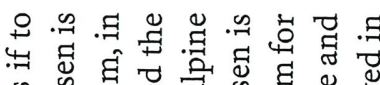

व

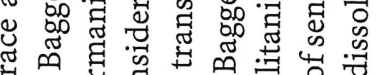

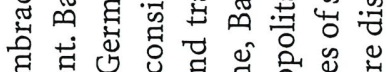

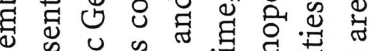

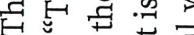

ن

की

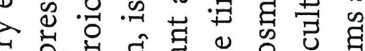

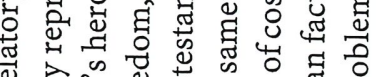

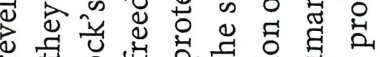

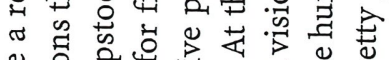

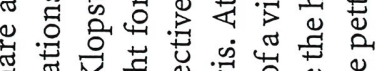

营氖氧

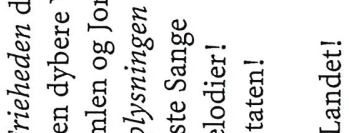

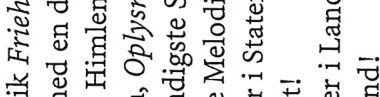

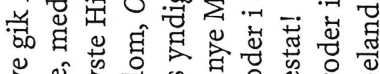

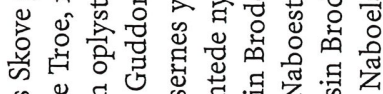

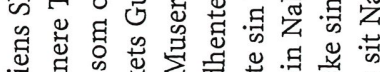

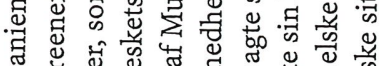

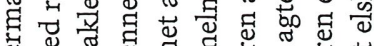

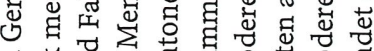

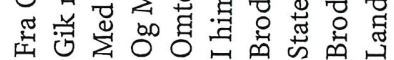

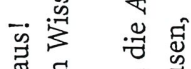

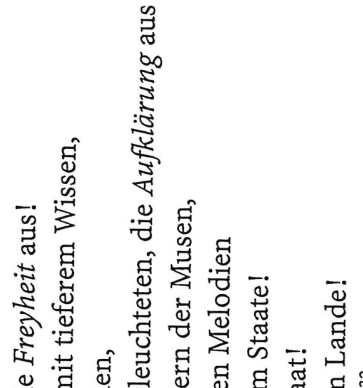

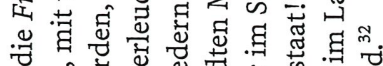

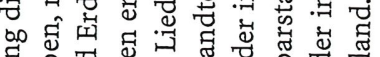

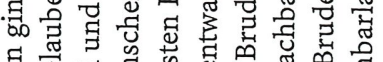

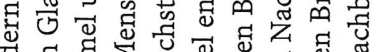

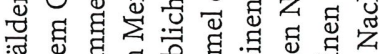

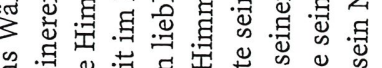

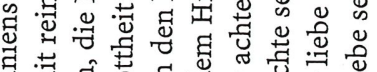

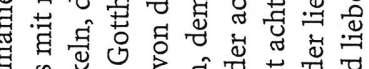

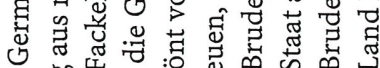

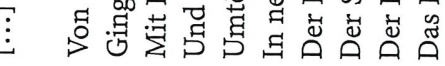

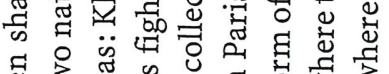
5 ळ.

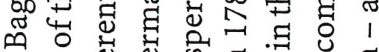

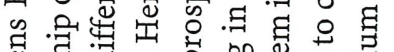

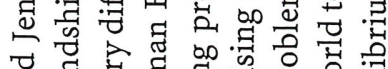

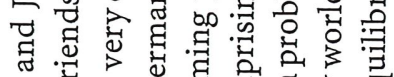

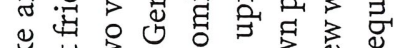

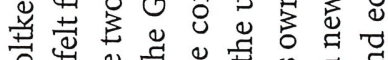

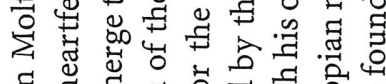

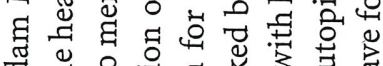

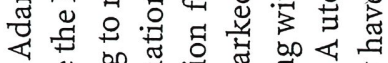

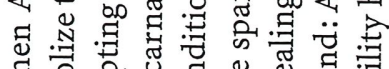

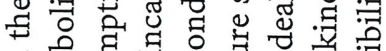

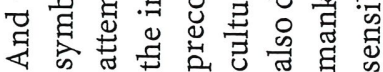

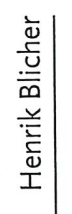

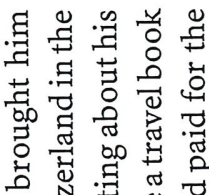

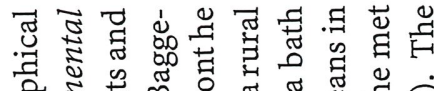

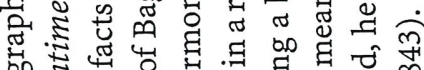

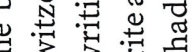

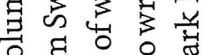

bo

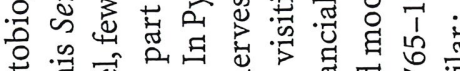

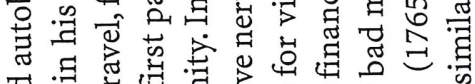

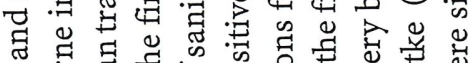

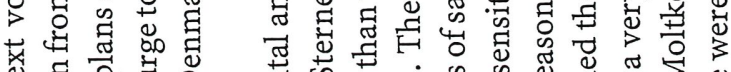

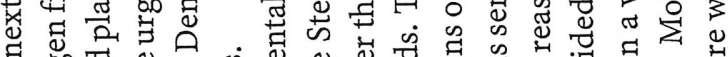

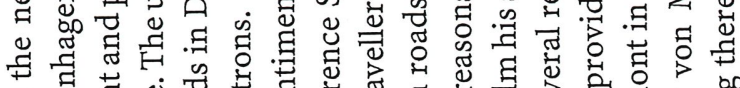
त

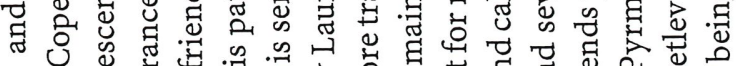

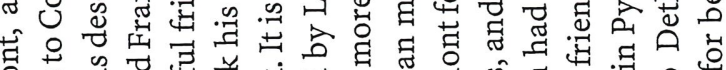

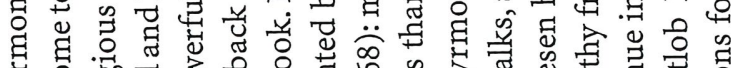

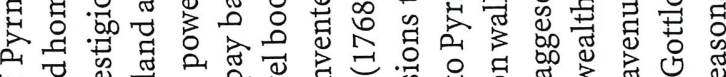

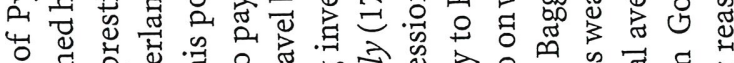

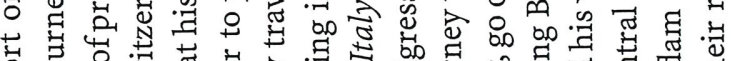

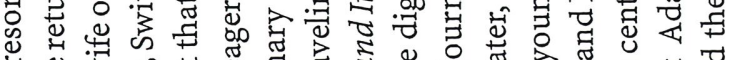

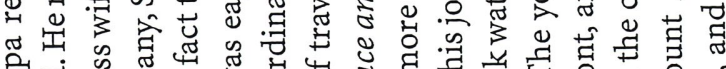

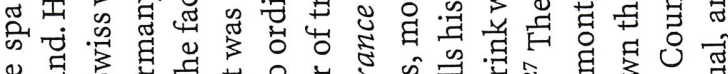

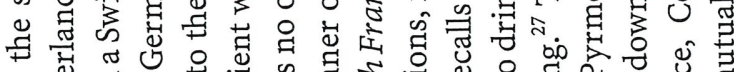

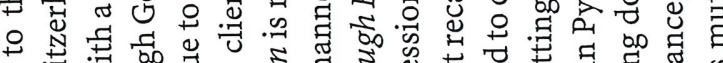

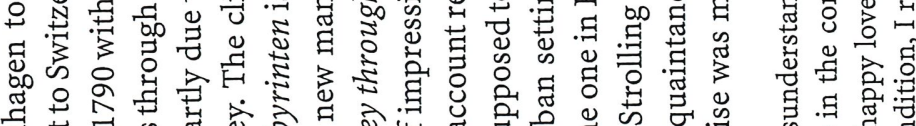

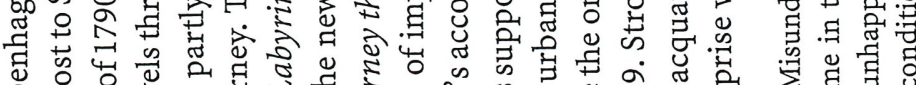

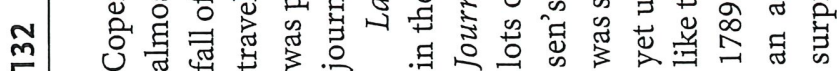

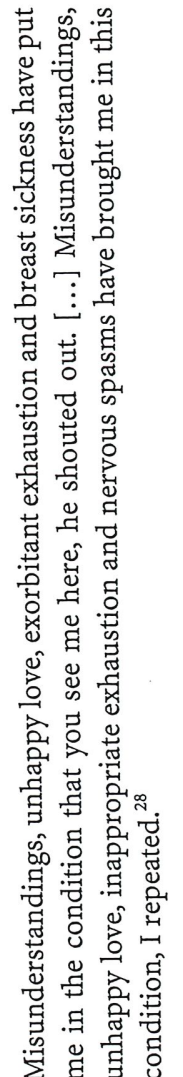

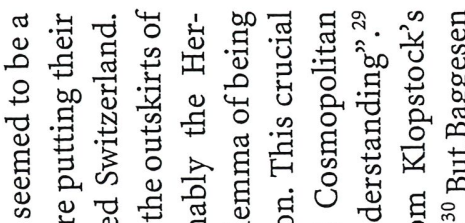
क

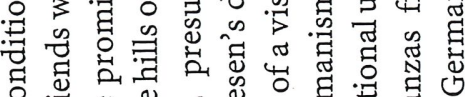

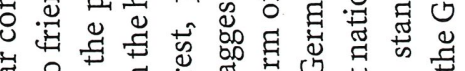

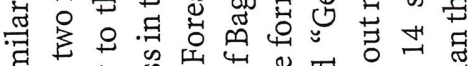

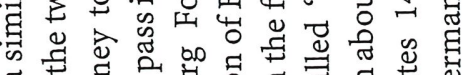

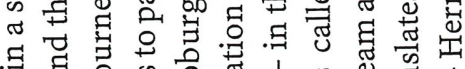

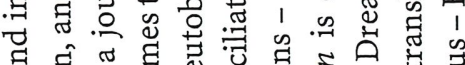

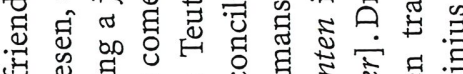

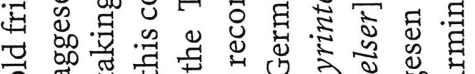
궁

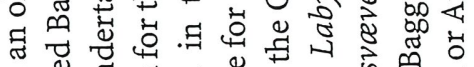

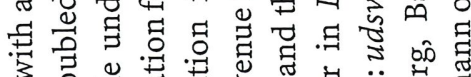

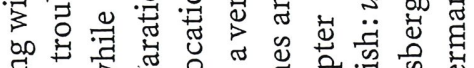

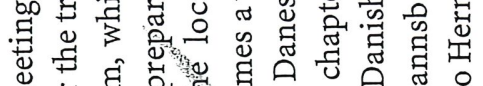

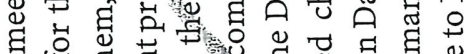

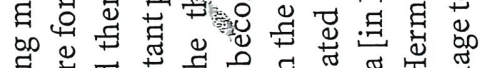

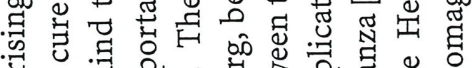

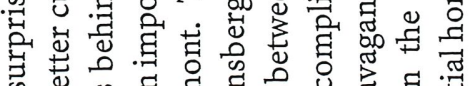

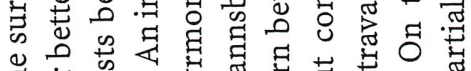

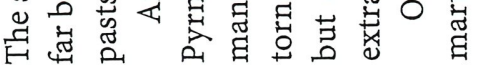

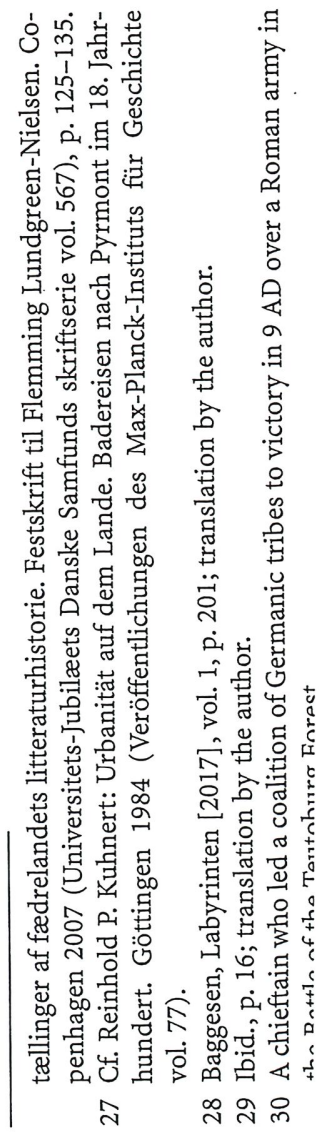



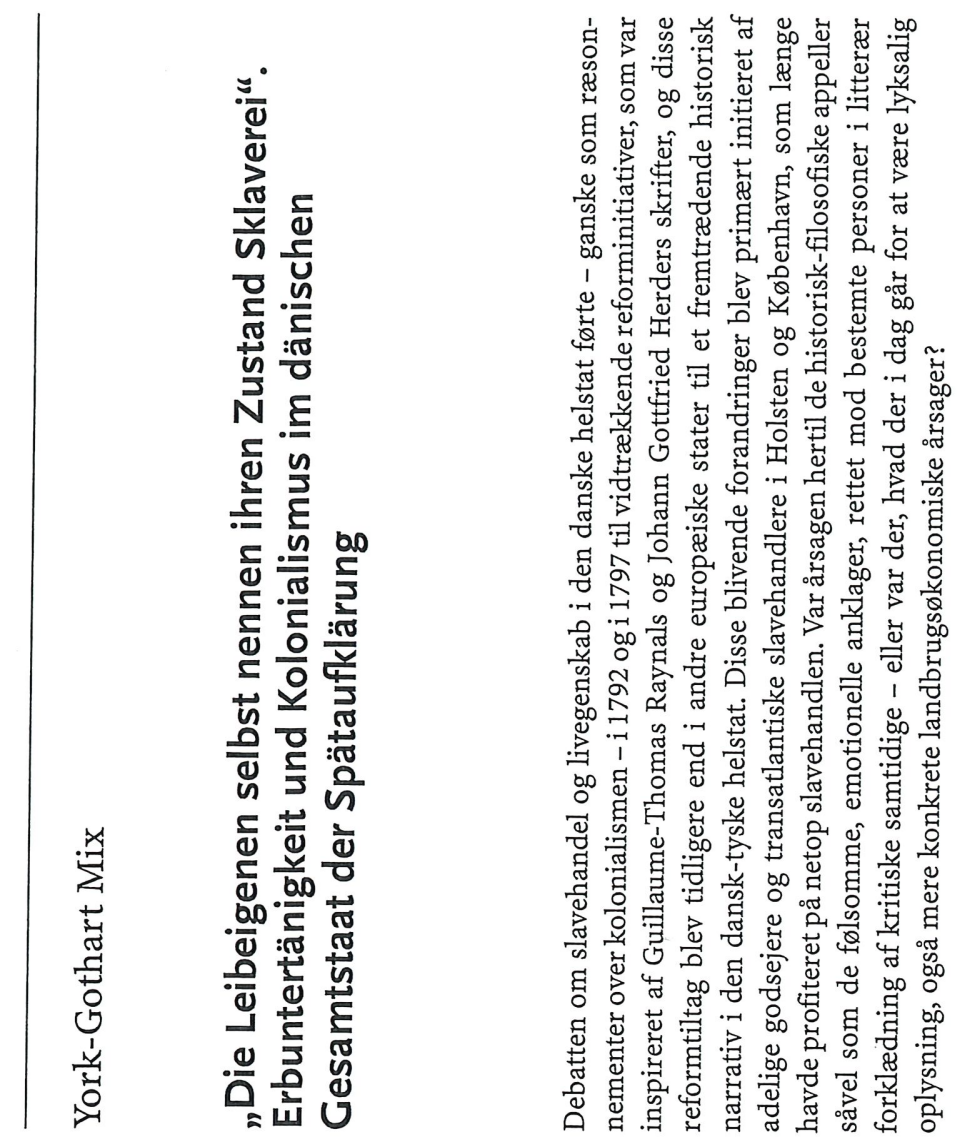

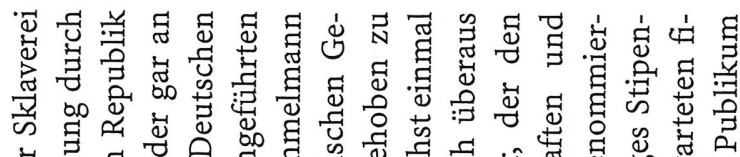

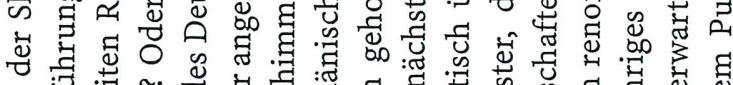

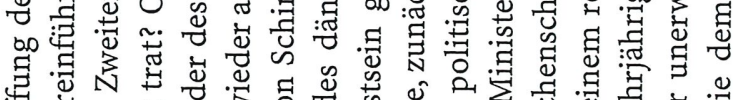

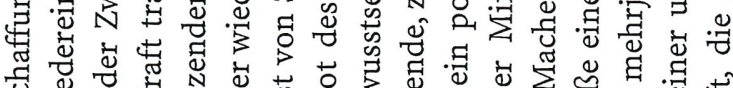

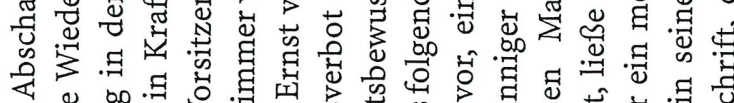
4

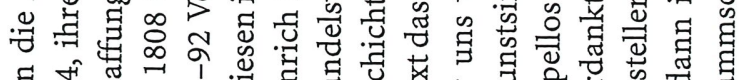

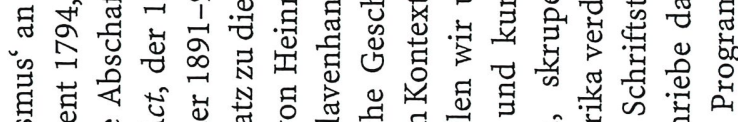

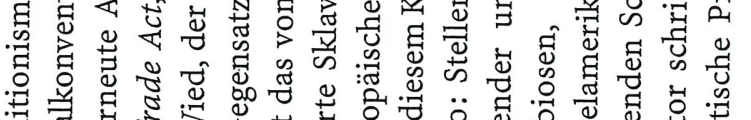

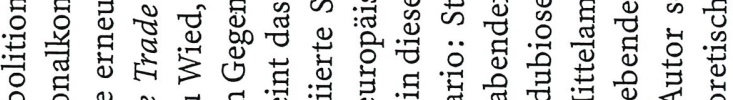

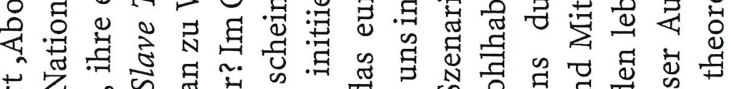

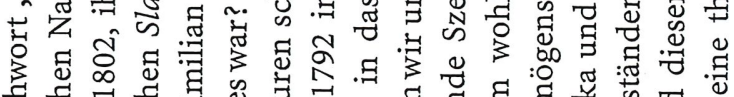

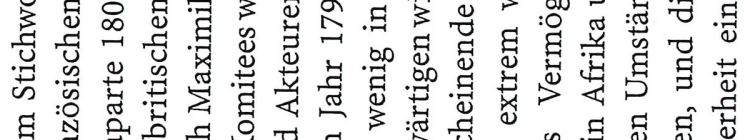

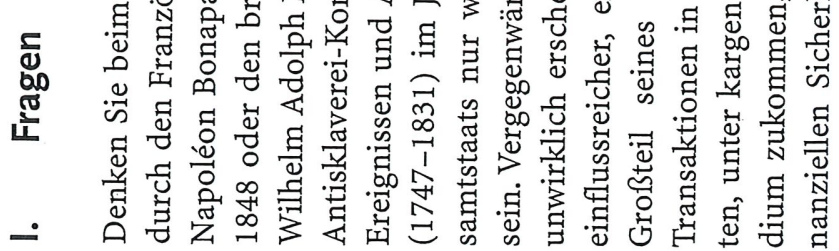

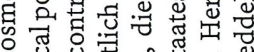

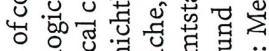

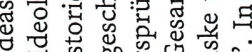

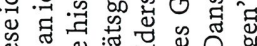

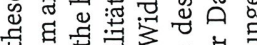

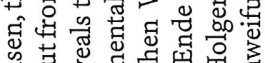

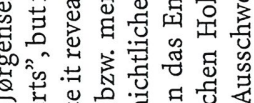

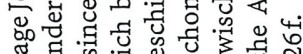
4 至

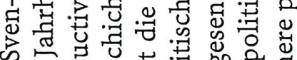
岁舟

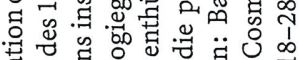

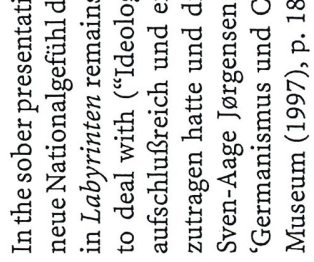



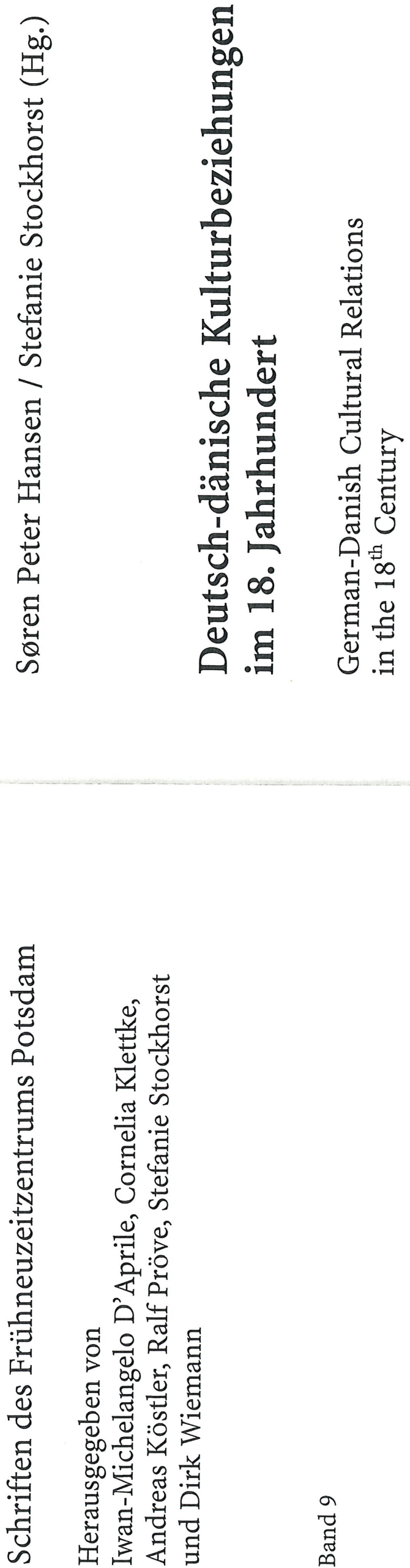

苂 